\title{
Effects of different kinds of polysaccharides on the properties and inhibition of Monilinia fructicola of the thyme essential oil-chitosan based composite films
}

\author{
Huan LIAN ${ }^{1,2}$, Jingying SHI ${ }^{1}$, Xiaoyan $\mathrm{ZHANG}^{1 *}$ (D), Yong $\mathrm{PENG}^{1 \star}$, Wenbo MENG ${ }^{1}$, Lingdong PEI
}

\begin{abstract}
In order to investigate the controlled release and antifungal effect of thyme essential oil on peach fruit, the four polysaccharides such as xanthan gum, gum tragacanth, arabic gum and pullulan were used to construct the essential oil-chitosan based composite film. The physical and chemical properties of composite film and its inhibition effect on Monilinia fructicola of peach fruit in vitro and in vivo were evaluated. The results showed that thyme essential oil contained some antifungal compounds such as 2-methoxy-3- (2-propenyl)-phenol, D-limonene and thymol. The addition of four polysaccharides decreased the tensile strength and elongation at break of composite film, and caused obvious fluctuation in the peak at 3263, 2884, 1552 and $1025 \mathrm{~cm}^{-1}$. Particularly, the strong interaction was found between chitosan and arabic gum which improved the antifungal effect of thyme essential oil in vitro. Moreover, the chitosan composite film combined with arabic gum exhibited the best inhibition effect on Monilinia fructicola of peach fruit in vivo regardless of the coating of film solution or film fumigation method. The work showed that chitosan-arabic gum composite film would be a potential application for improving the antifungal effect of essential oil on the preservation of peach fruit.
\end{abstract}

Keywords: thyme essential oil; polysaccharide film; Monilinia fructicola; peach fruit.

Practical Application: Provide a reference for the application of controlled release chitosan-essential oil composite film in peach fruit preservation.

\section{Introduction}

Peaches are one of the most popular fruits because of their rich nutrition and juicy taste. However, peaches are very sensitive to pathogens and are easy to decay during the storage after harvest, which cause a lot of economic loss (Mir et al., 2018). Fungi were the main factors that affected the postharvest decay of peaches. Among them, brown rot was the most common postharvest disease of peaches (Shi et al., 2020). At present, the main way to control this disease was still the use of chemical synthetic fungicides. But the continuous use of a large number of chemicals led to the increased resistance of pathogens infecting fruits, and also resulted in a potential threat to environmental safety and human health (Ali et al., 2018).

With the improvement of people's awareness of food safety, it was very important to adopt safe fresh-keeping measure. Plant essential oil was a natural plant extract originated from roots, stems, leaves and seeds. It had a strong antibacterial activity due to contain many active components such as phenols, terpenes and alkaloids (Brahmi et al., 2016; Song et al., 2019). In these plant essential oils, it was found that the antibacterial effect of thyme essential oil was better than lemon essential oil, cinnamon essential oil and other kinds of essential oils (Grande-Tovar et al., 2018; Peng \& Li, 2014). Moreover, thyme essential oil also showed a good inhibitory effect on fungi such as Botrytis cinerea and Penicillium finger in order to control the postharvest diseases of fruits and vegetables (Elshafie et al., 2015; Nikkhah et al., 2017).
Santoro et al. (2018) reported that thyme essential oil was treated as slow-release dispersant to evaluate the controlled effect on postharvest diseases of peaches and nectarines. Elshafie et al. (2015) found the antifungal activities of thyme and verbena essential oil were good against Monilinia laxa, Monilinia fructigena, and Monilinia fructicola. And the high concentration of verbena and thyme significantly decreased the plaque diameter of brown rot.

However, using plant essential oil alone was easy to cause the volatilization and waste of essential oil (Lian et al., 2019). Polysaccharide based film or coating was usually used as carrier to delay the release of essential oil, which could be applied to the preservation of postharvest fruits and vegetables. Among them, chitosan has good antibacterial and antioxidant capacity. Many studies have found that chitosan films or film-forming solution could inhibit the growth of most bacteria and fungi, extend the storage period and protect the quality of fruits and vegetables (Wang et al., 2020; Kaewklin et al., 2018). Chitosan films combined with plant essential oil had better antifungal effect, which could inhibit the decay of peaches, strawberries, grapes and other fruits after harvest (Lian et al., 2020; Munhuweyi et al., 2017). Rahimi et al. (2019) reported the composite treatment of chitosan and thymol had better antifungal effect than that of chitosan or thymol alone. The shelf-life of peach fruit treated by the combination of chitosan and thymol was also the highest. However, whether other controlled agents can enhance the 
antifungal effect of thyme essential oil-chitosan based composite films was still little reported.

It was also found that other polysaccharides, such as xanthan gum and arabic gum, could be combined with chitosan to improve the mechanical properties, water and gas resistance of chitosan films (Lima et al., 2017; Hosseini et al., 2015). Lima et al. (2017) reported that xanthan gum could improve the tensile strength of films due to the polyelectrolyte characteristic with opposite charges between them. In addition, many reports also found that plant gum such as arabic gum and guar gum could be added into chitosan films and improve the tensile strength and gas barrier property of films (Xu et al., 2018). However, it was not clear whether the addition of these polysaccharides into chitosan-essential oil film was also conducive to delay the release of essential oil, so as to play a better antifungal effect on perishable fruits.

This research was to prepare the essential oil-chitosan based composite films with four kinds of polysaccharides, to investigate the performance and structure of composite films, to analyze the synergistic controlled release and antifungal effect on brown rot (Monilinia fructicola) of peach fruit in vitro and in vivo.

\section{Materials and methods}

\subsection{Materials}

Chitosan with 90\% deacetylation degree, xanthan gum, arabic gum, tragacanth gum, pullulan polysaccharide, Tween 80 were provided by Shanghai Yuanye Biotechnology Co., Ltd. (Shanghai, China). Thyme essential oil was purchased from Guangzhou Wenling Trading Co., Ltd. (Guangzhou, China). Monilinia fructicola was a preserved strain in the Postharvest Preservation Engineering Laboratory of Shandong Agricultural University. Peaches (Prunus persica (L.) Batsch cv. 'Lumi') were purchased from the local fruit wholesale market.

\subsection{Composition analysis of thyme essential oil}

The components of thyme essential oil were carried out by a GCMS-QP 2010 gas chromatogram and mass spectrometer (Shimadzu Co., Ltd) combined with headspace solid-phase microextraction. Thyme essential oil was put into a $200 \mathrm{~mL}$ glass bottle with sealed rubber plug and extracted for 30 mins at $60^{\circ} \mathrm{C}$.

The chromatographic condition was Rex-5 column $(30 \mathrm{~m} \times 0.32 \mathrm{~mm} \times 0.25 \mu \mathrm{m})$, helium as carrier gas and flow rate $2.97 \mathrm{~mL} / \mathrm{min}$. The initial temperature was set to $35^{\circ} \mathrm{C}$ and kept for $3 \mathrm{mins}$, then the temperature was increased to $140{ }^{\circ} \mathrm{C}$ at a speed of $6^{\circ} \mathrm{C} / \mathrm{min}$ and raised to $230^{\circ} \mathrm{C}$ at a speed of $10^{\circ} \mathrm{C} / \mathrm{min}$ and kept for $6 \mathrm{~min}$. The mass spectrometry condition was $200^{\circ} \mathrm{C}$ ion source temperature and $250^{\circ} \mathrm{C}$ interface temperature, $70 \mathrm{eV}$ electronic energy and 45-450 amu/s mass range. The qualitative analysis was performed by NIST mass spectrometry library.

\subsection{Preparation of film-forming solution and films}

Weighed $1.2 \mathrm{~g}$ of chitosan powder and poured it into a beaker, then slowly added $150 \mathrm{~mL}$ of glacial acetic acid solution $(1.0 \%$, v/v distilled water). Four other polysaccharides were dissolved in $150 \mathrm{~mL}$ distilled water and then mixed with chitosan solution by magnetic stirrer at room temperature until it was completely dissolved. Then, glycerol $(30 \%, \mathrm{w} / \mathrm{w})$ was added and stirred for $0.5 \mathrm{~h}$. After mixing the Tween $80(0.2 \%$, w/v) with thyme essential oil $(1 \%, w / v)$, the mixture was added to the chitosan solution, and continued stirring until dissolved. All film solutions were homogenized at $12000 \mathrm{rpm}$ for 4 mins with a high-speed disperser (IKA T18-Digital Ultra-Turrax, Staufen, Germany), and then vacuumed for 30 mins with a SHZ-D vacuum pump (Shanghai Yuying Instruments Co., Ltd. Shanghai, China) to remove bubbles. Finally, the film solution was poured on a self-made glass plate $(25 \mathrm{~cm} \times 25 \mathrm{~cm} \times 1 \mathrm{~cm})$ and dried at room temperature. The removed films were stored in a dryer (saturated magnesium nitrate solution, 53\% humidity) at room temperature for at least $48 \mathrm{~h}$ and then the next test was performed.

Thyme essential oil-chitosan composite films with different kinds of polysaccharides including CK, C-Xg, C-P, C-Gt and $\mathrm{C}-\mathrm{Ag}$ were shown in the Table 1 below.

\subsection{Physical properties of composite films}

According to the methods of Peng et al. (2020), the performance indexes of film solution and films were determined. The thickness of the film was measured at six random points by a digital helical micrometer (Shanghai Merris Hardware Tools Co., Ltd., Shanghai, China). The water vapor permeability (WVP) of the film was measured by cup method and expressed by the mass of water absorbed by anhydrous calcium chloride. The tensile properties including tensile strength (TS) and elongation at break (EAB) were tested by XLW tension tester (Labthink Instruments Co. Ltd, Jinan, China) at a speed of $10 \mathrm{~mm} / \mathrm{min}$.

\subsection{Chemical structure of composite films}

The chemical structure of the composite film was analyzed by FTIR. Before the test, the film sample was cut into $20 \mathrm{~mm} \times$ $20 \mathrm{~mm}$ square and scanned with total reflection mode of FTIR. Set the spectral resolution to $4 \mathrm{~cm}^{-1}$, scan 32 times in the range of $4000-550 \mathrm{~cm}^{-1}$ to obtain the infrared spectrum curve.

\subsection{Inhibition of composite film on Monilinia fructicola}

\section{Preparation of Monilinia fructicola}

The preparation of Monilinia fructicola according to the method of Zheng et al. (2013) with slight modification. The preserved Monilinia fructicola was activated in PDA medium and used after two weeks. The spores of pathogenic bacteria were isolated from the culture medium and suspended in sterile water. The suspension was filtered with a sterile filter screen in order

Table 1. Film forming component and nomenclature.

\begin{tabular}{ccc}
\hline Name & Chitosan (w/v) & Polysaccharides (w/v) \\
\hline CK & $1.8 \%$ & - \\
C-Xg & $1.2 \%$ & $0.6 \%$ Xanthan gum \\
C-P & $1.2 \%$ & $0.6 \%$ Pullulan \\
C-Gt & $1.2 \%$ & $0.6 \%$ Gum tragacanth \\
C-Ag & $1.2 \%$ & $0.6 \%$ Arabic gum \\
\hline
\end{tabular}


to remove the mycelium. The required spore concentration was regulated by a blood cell counting plate before using.

\section{Inhibitory effect of composite film solutions on Monilinia fructicola in vitro}

The composite film solutions and PDA medium cooled to about $50{ }^{\circ} \mathrm{C}$ were mixed in a volume ratio of $1: 100$ and then poured into the plate. The control group was added with sterile water of equal volume. The Monilinia fructicola, which had been cultured in advance, was perforated with a hole punch with a diameter of $8 \mathrm{~mm}$. The cake was inoculated into the center of PDA plate and cultured at $25^{\circ} \mathrm{C}$ and $80 \%$ relative humidity. After $24 \mathrm{~h}$, observed once every $24 \mathrm{~h}$, measured the colony diameter and took photos. Repeated 3 times for each treatment. And the untreated control with bacteria was named $\mathrm{CK}_{2}$.

\section{Effects of film solutions coating on Monilinia fructicola in vivo}

According to the method of Liu et al. (2018), the bacteriostatic in vivo experiment was carried out with slight modification. The peach fruits with the same maturity, similar size, no pests and mechanical damage were soaked in $150 \mathrm{ppm}$ sodium hypochlorite solution for 2 min, washed twice with distilled water, and dried naturally in the ventilated place. In the center of fruit surface on the equatorial side of each fruit, 3 holes were punctured with sterilized forceps, which were triangular in shape, close in distance and about $4 \mathrm{~mm}$ in depth. $10 \mu \mathrm{L}$ of diluted 100 fold film solution was injected into the pricking hole of the peel. After $4 \mathrm{~h}, 5 \times 10^{4}$ sporangia/mL of spore suspension of Monilinia fruticola was inoculated. After the bacteria liquid entered the peach fruit, the fruit was put in the airtight container $(2.6 \mathrm{~L})$ and stored in a constant temperature and humidity chamber at $25^{\circ} \mathrm{C}$ and $80 \%$ relative humidity. The diameter of the lesion was measured and photographed at $48 \mathrm{~h}$ and $72 \mathrm{~h}$, respectively. There were 6 fruits in each group, which were repeated three times, and the untreated control with bacteria was named $\mathrm{CK}_{2}$ and the blank control group was set.

\section{Effects of composite film fumigation on Monilinia fructicola in vivo}

The same processing above, $20 \mu \mathrm{L}$ spore suspension of Monilinia fruticola $\left(5 \times 10^{4}\right.$ sporangia/mL) to the pricking hole of the peel. After the bacteria liquid entered the peach, the fruits were put in the airtight container $(2.6 \mathrm{~L})$. Stuck the film $(4 \mathrm{~cm} \times 4 \mathrm{~cm})$ on the inside of the cover cap, avoided contacting the fruit, and tried to make the essential oil diffuse evenly.

For further determining the fumigation size of film, attached different areas of films $(1 \mathrm{~cm} \times 1 \mathrm{~cm}, 2 \mathrm{~cm} \times 2 \mathrm{~cm}, 4 \mathrm{~cm} \times 4 \mathrm{~cm}$, $6 \mathrm{~cm} \times 6 \mathrm{~cm}$ ) to the inner surface of the lid, avoided contact with the fruit and tried to spread the essential oil evenly. The fruits were stored in a constant temperature and humidity box at $25^{\circ} \mathrm{C}$ and $80 \%$ relative humidity. The diameter of the lesion was measured and photographed at $48 \mathrm{~h}$ and $72 \mathrm{~h}$ respectively. Each group had 6 fruits, which were repeated three times, and the control was set.

\subsection{Statistical analysis}

All data were processed with Microsoft Excel 2010. And the data were analyzed by ANOVA by means of the SPSS software (version 24.0). $P<0.05$ was considered significant.

\section{Results and discussion}

\subsection{Components of thyme essential oil}

As shown in Table 2, eighteen components were found in thyme essential oil used in this work which included nine alkenes, two phenols and two alcohols. Among them, 2-methoxy-3 -(2-propenyl)-phenol (21.81\%), D-limonene (19.24\%), thymol (8.28), caryophyllene (8.82\%) and 4-methylene-1-(1methylethyl)-bicyclo hexane (8.99\%) were main components of thyme essential oil. Elshafie et al. (2015) reported that o-cymene and carvacrol was the main components of thyme oil (Thymus vulgaris) which accounting for $56.2 \%$ and $24.4 \%$, respectively. However, three different kinds of thymus species (T. vulgare, T. citriodorus and T. serpyllum) included 22 volatile components mainly consisting of geraniol, thymol, $\alpha$-terpinene and linalool (De Lisi et al., 2011). The difference could be attributed to many factors such as growth condition, different parts of plant tissue and extraction methods. In any case, the phenol and alkene were important antimicrobial components in thyme essential oil.

\subsection{Physical properties of composite films}

Note: the date used in the table come from our previous work. The different lowercase at the end of each column means the different significance.

As can be seen from Table 3, the thickness of CK film was $0.089 \mathrm{~mm}$, and there is no significant difference in the thickness between C-Ag film and the CK film ( $p>0.05)$. The addition of xanthan gum, pullulan polysaccharide and gum tragacanth increased the thickness of composite film. Compared with the CK film, the thickness of C-Gt film was the largest, with a value of $0.20 \mathrm{~mm}$, increased by 2.3 times. The change of the thickness might be related to the interaction of chitosan and other polysaccharides.

The water vapor permeability (WVP) of the CK film was $2.45 \times 10^{-10} \mathrm{~g} /(\mathrm{m} \cdot \mathrm{s} \cdot \mathrm{pa})$. The addition of xanthan gum and gum tragacanth increased the WVP of composite films. The WVP of $\mathrm{C}-\mathrm{Xg}$ film was the highest, with the value of $3.74 \times 10^{-10} \mathrm{~g} /(\mathrm{m} \cdot \mathrm{s} \cdot \mathrm{pa})$. On the contrary, the WVP of C-Ag and C-P composite films decreased by $20.0 \%$ and $4.9 \%$, respectively, compared with CK film. The hydrogen bonding and electrostatic interaction between chitosan and thyme essential oil could be disturbed by the addition of as xanthan gum and tragacanth gum, which led to the micro phase separation and increased the WVP of the composite film (Santoso et al., 2019; Shih et al., 2009). The low WVP of C-Ag film might be due to the interaction between $\mathrm{COO}^{-}$loaded by polyanion arabic gum and $\mathrm{NH}_{4}^{+}$loaded by chitosan, which hindered the interaction between water molecules and polar groups in film matrix (Xu et al., 2020). However, there was no significant difference between the control film and the C-Ag film.

The tensile strength and elongation at break of CK film was the highest, with the value of $21.94 \mathrm{Mpa}$ and $36.68 \%$, respectively. The addition of other polysaccharides reduced the tensile strength and elongation at break of composite films, which the C-Gt film had the lowest tensile strength (7.32 Mpa) and elongation at break (6.08\%). Compared with other treatments, the tensile strength of C-Ag film was relatively higher than that of $\mathrm{C}-\mathrm{Xg}$, $\mathrm{C}-\mathrm{P}$ and $\mathrm{C}-\mathrm{Gt}$ film. This showed that the interaction between 
Table 2. Components of thyme essential oil.

\begin{tabular}{|c|c|c|c|c|}
\hline No. & $\begin{array}{c}\text { Retention } \\
\text { time(min) }\end{array}$ & Name & Peak area & Percentage $(\%)$ \\
\hline 1 & 16.784 & Alpha-pinene & 26148258 & 7.17 \\
\hline 2 & 17.416 & 2,2-dimethyl-3-methylene-, (1S)-bicyclo heptane & 19994758 & 5.48 \\
\hline 3 & 18.497 & 4-methylene-1-(1-methylethyl)-bicyclo hexane & 32785354 & 8.99 \\
\hline 4 & 18.676 & Beta-pinene & 16379055 & 4.49 \\
\hline 5 & 18.991 & Beta-myrcene & 12175860 & 3.34 \\
\hline 6 & 20.950 & D-limonene & 70137614 & 19.24 \\
\hline 7 & 21.026 & Eucalyptol & 7309187 & 2.00 \\
\hline 8 & 21.281 & 1,3,6-Octatriene, 3,7-dimethyl-, (Z)- & 2126037 & 0.58 \\
\hline 9 & 21.848 & Gamma-terpinene & 4482620 & 1.23 \\
\hline 10 & 23.114 & 2-ethenyl-1,3-dimethyl-benzene & 11391064 & 3.12 \\
\hline 11 & 23.335 & Linalool & 2979374 & 0.82 \\
\hline 12 & 30.738 & Thymol & 30179907 & 8.28 \\
\hline 13 & 33.316 & 2-methoxy-3-(2-propenyl)-phenol & 79482745 & 21.81 \\
\hline 14 & 33.613 & Copaene & 2089026 & 0.57 \\
\hline 15 & 34.938 & Caryophyllene & 32139794 & 8.82 \\
\hline 16 & 35.630 & Humulene & 11164024 & 3.06 \\
\hline 17 & 36.861 & 1,2,3,5,6,8a-hexahydro-4,7-dimethyl-1-(1-methylethyl)-, (1S-cis)-naphthalene & 1223233 & 0.34 \\
\hline 18 & 38.158 & Caryophyllene oxide & 2389113 & 0.66 \\
\hline
\end{tabular}

Table 3. Physical properties of thyme essential oil-chitosan based composite films with different kinds of polysaccharides.

\begin{tabular}{ccccc}
\hline Treatments & Thickness $/ \mathrm{mm}$ & WVP $/ 10^{-10} \mathrm{~g} /(\mathrm{m} \cdot \mathrm{s} \cdot \mathrm{pa})$ & Tensile strength/Mpa & Elongation at break $/ \%$ \\
\hline CK & $0.089 \pm 0.002^{\mathrm{d}}$ & $2.45 \pm 0.26^{\mathrm{c}}$ & $21.94 \pm 4.28^{\mathrm{a}}$ & $36.68 \pm 10.49^{\mathrm{a}}$ \\
C-Xg & $0.151 \pm 0.016^{\mathrm{b}}$ & $3.74 \pm 0.34^{\mathrm{a}}$ & $10.04 \pm 1.51^{\mathrm{cd}}$ & $11.36 \pm 1.43^{\mathrm{b}}$ \\
C-P & $0.124 \pm 0.009^{\mathrm{c}}$ & $2.33 \pm 0.09^{\mathrm{c}}$ & $13.23 \pm 1.12^{\mathrm{c}}$ & $6.33 \pm 1.43^{\mathrm{c}}$ \\
C-Gt & $0.202 \pm 0.011^{\mathrm{a}}$ & $3.10 \pm 0.18^{\mathrm{b}}$ & $7.32 \pm 0.78^{\mathrm{d}}$ & $6.08 \pm 1.44^{\mathrm{c}}$ \\
C-Ag & $0.081 \pm 0.006^{\mathrm{d}}$ & $1.96 \pm 0.55^{\mathrm{c}}$ & $18.03 \pm 4.24^{\mathrm{b}}$ & $12.48 \pm 3.96^{\mathrm{b}}$ \\
\hline
\end{tabular}

the molecular chains of chitosan was stronger than that of chitosan and other polysaccharides, resulting in the lower tensile strength of the treatment group. In addition, the elongation at break of film was also related to the hydrogen bond in the film substrate (Nascimento et al., 2020; Hosseini et al., 2015), the added polysaccharide could block the hydrogen bond of chitosan-essential oil composite film and reduce the mobility of film matrix (Lima et al., 2017).

\subsection{Chemical structure of composite films}

From Figure 1, there are similar spectral characteristics from $550 \mathrm{~cm}^{-1}$ to $4000 \mathrm{~cm}^{-1}$ between the control group and the treatment group. For the control chitosan film (CK), the characteristic peak of chitosan film mainly occurred at the region of $1635 \mathrm{~cm}^{-1}$ (Amide I) and $1552 \mathrm{~cm}^{-1}$ (Amide II, Bending vibration of N-H bond). In addition, the characteristic peaks at 3263, 2920 and 2884, 1406 and $1025 \mathrm{~cm}^{-1}$ were attributed to $\mathrm{O}-\mathrm{H}$ stretching (hydrogen bond), $\mathrm{C}-\mathrm{H}$ stretching, $-\mathrm{CH}_{2}$ bending, $-\mathrm{CH}_{3}$ symmetric deformation and C-O stretching, respectively (Priyadarshi et al., 2018).

After adding polysaccharide, the peak at 3263, 2884, 1552 and $1025 \mathrm{~cm}^{-1}$ showed obvious fluctuation compared other peaks. The peak at $3263 \mathrm{~cm}^{-1}$ shifted to higher wavelength region with the addition of four polysaccharides $\left(3265,3271,3266\right.$ and $3272 \mathrm{~cm}^{-1}$ for $\mathrm{C}-\mathrm{Xg}, \mathrm{C}-\mathrm{P}, \mathrm{C}-\mathrm{Gt}$ and C-Ag, respectively). This showed that the strong hydrogen bonding interaction occurred between chitosan and other polysaccharides. Moreover, N-H bending (Amide II) in chitosan was also impacted by the addition of four polysaccharide.
The peak shifted from $1552 \mathrm{~cm}^{-1}$ to high wavelength region (1556 or $1557 \mathrm{~cm}^{-1}$ ). However, the addition of four polysaccharides had little effect on the peak of Amide I. In addition, the xanthan gum and gum tragacanth caused obvious changes in $2884 \mathrm{~cm}^{-1}$ compared with pullulan and arabic gum which meant $\mathrm{C}-\mathrm{H}$ bending was affected by the interaction between chitosan and xanthan gum (or gum tragacanth). The fingerprint area in $1025 \mathrm{~cm}^{-1}$ showed the most significant change with the addition of pullulan compared with other polysaccharides. Xu et al. (2018) reported that the more interaction sites existed between arabic gum and chitosan, and charge interaction between them improved the compatibility of film matrix. Lima et al. (2017) also reported chitosan and xanthan gum were polyelectrolytes with opposite charge. The amino group of chitosan carried a positive charge when the $\mathrm{pH}$ value is lower than 6.5, so it could combine with carboxylic acid group of xanthan gum. The mixture of polyelectrolyte with opposite charge produced polyelectrolyte complex. The corresponding structural formula of main compounds in four polysaccharides was listed in Figure 2.

\subsection{Inhibition of film solution on the mycelial growth of Monilinia fructicola in vitro}

As can be seen from Table 4 and Figure 3, the growth of Monilinia fructicola was inhibited obviously by adding chitosanessential oil composite film solution. The edge of the pathogen colony was pigmented, and the mycelium was atrophic and aged. There was no significant difference between CK, C-Xg, 
$\mathrm{C}-\mathrm{P}$ and $\mathrm{C}-\mathrm{Gt}$ plaque diameter ( $\mathrm{p}>0.05)$. The plaque diameter with the treatment of C-Ag film solution was smaller than that of other groups. This showed the addition of arabic gum into chitosan film solution improved the antifungal activity of essential oil composite film solution. This could be due to the electrostatic interaction between arabic gum and chitosan which delayed the release of thyme essential oil from composite film (Xu et al. 2018). Arabic gum possessed more negative charges for the interactions with polycationic chitosan (Tan et al., 2016; Tsai et al., 2014).

\subsection{Effects of film solutions coating on Monilinia fructicola in vivo}

As shown in Figure 4, the lesion diameter of control group reached $31.92 \mathrm{~mm}$ at the end of $72 \mathrm{~h}$. The lesion diameter of peach fruit treated with four polysaccharides was lower than that of control group. The peach fruit treated with C-Ag film solution still had no spots compared with other groups. According to the inhibiting effect, the lesion diameter treated with CK film solution reached $1 / 2$ of whole fruit at $72 \mathrm{~h}$. Therefore, we continued to lay aside the treated peach fruit with C-Ag film solution and found that it took $144 \mathrm{~h}$ to reach the same lesion diameter. This exhibited that C-Ag film could extend the shelf life for $72 \mathrm{~h}$ compared with the control. The results were similar with the mycelial growth in vitro. Perdones et al. (2012) also found the film solution coated with chitosan and lemon essential

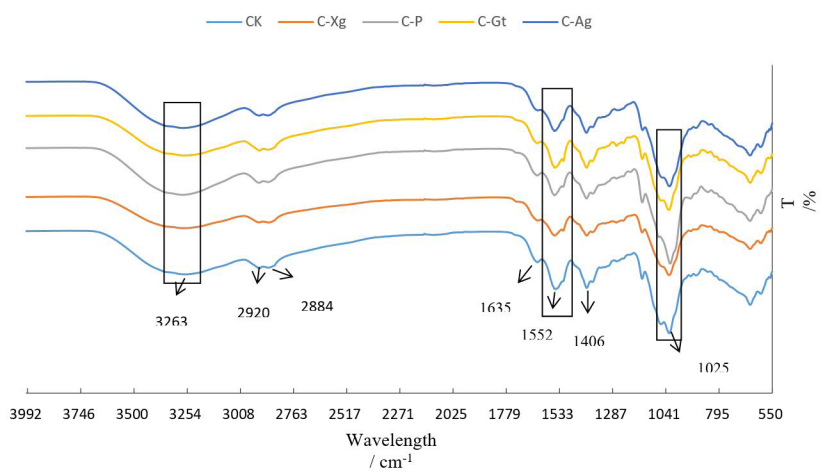

Figure 1. FTIR spectra image of thyme essential oil-polysaccharide based composite films. oil had better antibacterial effect in vitro and in vivo. So the controlled release of thyme essential oil in composite films plays an important role during the storage of peach fruit.

\subsection{Effects of composite film fumigation on Monilinia fructicola in vivo}

As shown in Figure 5, the lesion diameter in the control group was $35.52 \mathrm{~mm}$ at $72 \mathrm{~h}$. The lesion diameter fumigated by essential oil-composite films was significantly smaller than that in the control group. After treated with $48 \mathrm{~h}$, except for the C-Ag treatment group, there was no significant difference in lesion diameter among these treatments $(p>0.05)$. At the end of $72 \mathrm{~h}$, C-Ag film and C-P film had the strongest inhibitory effect on the lesion spread of fruit, particularly C-Ag film. The results showed that film fumigation combined with chitosan and arabic gum could enhance the antifungal effect of thyme essential oil on peach fruit. Similar results were also found in fresh-cut pear with the fumigation treatment of chitosan and cinnamon oil composite film (Xu et al., 2013).

In order to further investigate the actual application of C-Ag film, we set different size of film for fumigation treatment. As can be seen from Figure 6, the lesions diameter decreased with the increase of the C-Ag film area. When treated with $48 \mathrm{~h}$, no spots were found in peach fruit by the fumigation of $4 \mathrm{~cm} \times 4 \mathrm{~cm}$ and $6 \mathrm{~cm} \times 6 \mathrm{~cm}$ films. At $72 \mathrm{~h}$, the lesion diameter of peach fruit fumigated with $4 \mathrm{~cm} \times 4 \mathrm{~cm}$ and $6 \mathrm{~cm} \times 6 \mathrm{~cm}$ film was the smallest and there was no significant difference between the two treatments $(\mathrm{P}>0.05)$. Therefore, according to the antifungal effect, the film area of $4 \mathrm{~cm} \times 4 \mathrm{~cm}$ was potential selected for the practical application.

Table 4. Effect of film-forming solution on the plaque diameter of Monilinia fructicola.

\begin{tabular}{crr}
\hline Treatments & $72 \mathrm{~h} / \mathrm{mm}$ & \multicolumn{1}{c}{$96 \mathrm{~h} / \mathrm{mm}$} \\
\hline CK2 & $24.20 \pm 5.76^{\mathrm{a}}$ & $34.94 \pm 4.70^{\mathrm{a}}$ \\
CK & $13.31 \pm 2.40^{\mathrm{b}}$ & $21.66 \pm 3.37^{\mathrm{b}}$ \\
C-Xg & $14.59 \pm 0.55^{\mathrm{b}}$ & $22.69 \pm 3.64^{\mathrm{b}}$ \\
C-P & $16.05 \pm 0.81^{\mathrm{b}}$ & $24.68 \pm 1.21^{\mathrm{b}}$ \\
C-Gt & $15.11 \pm 1.36^{\mathrm{b}}$ & $24.23 \pm 2.72^{\mathrm{b}}$ \\
C-Ag & $1.92 \pm 1.76^{\mathrm{c}}$ & $6.30 \pm 0.97^{\mathrm{c}}$ \\
\hline
\end{tabular}<smiles>COC1OC(CO)C(OC2OC(CO)C(OC)C(O)C2O)C(O)C1O</smiles>

Xanthan gum

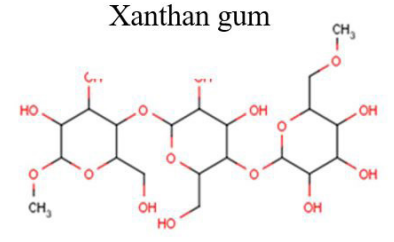

Pullulan<smiles>CCC(C)O</smiles>

Chitosan

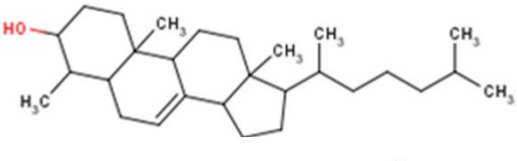

Gum tragacanth<smiles>COC(=O)c1nc2cc(C)c3cccnc3c2o1</smiles>

Arabic gum

Figure 2. Structural formula of chitosan and other four polysaccharides. 

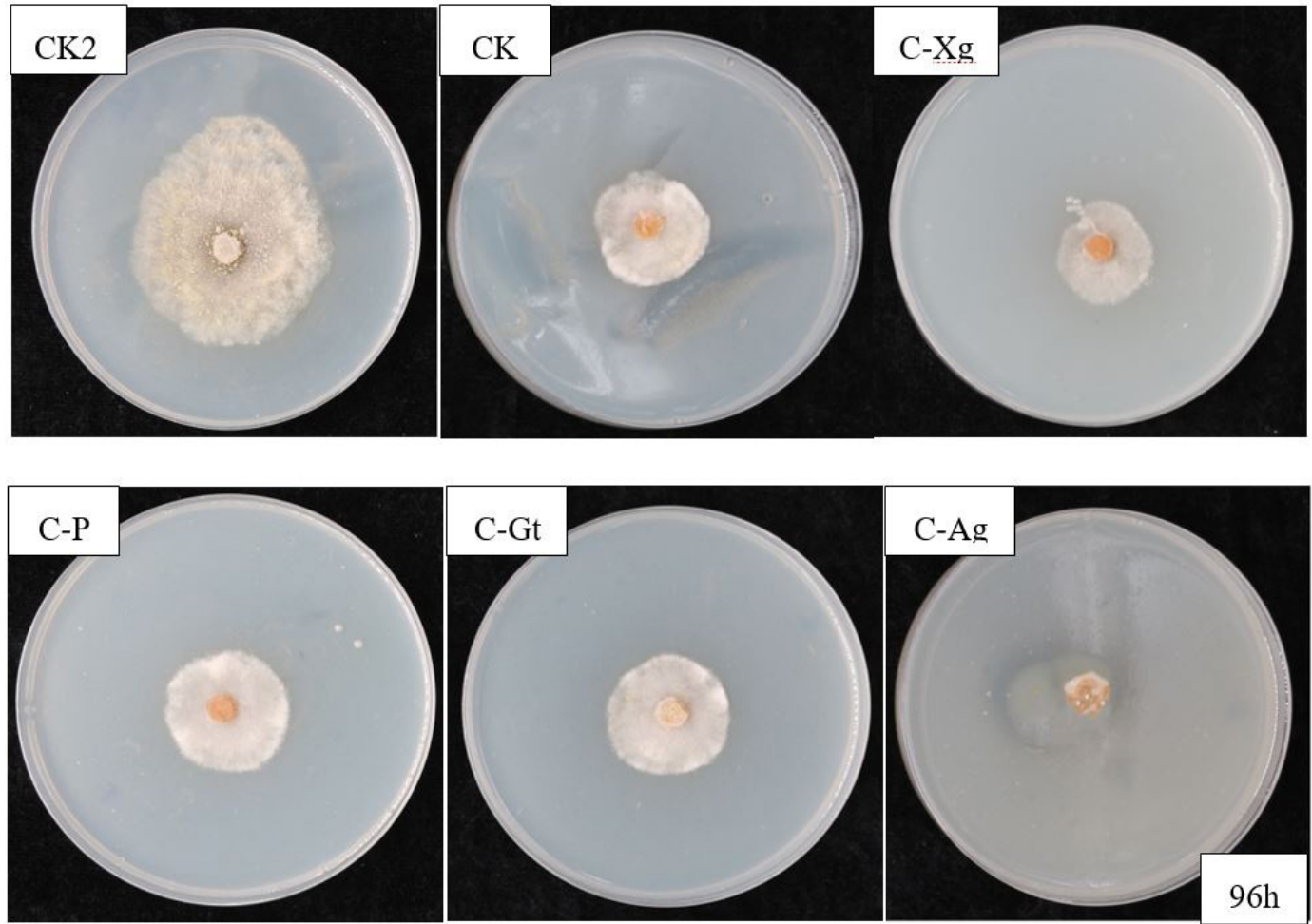

Figure 3. Inhibition of film-forming solution on the mycelial growth of Monilinia fructicola.

$48 \mathrm{~h}$ $72 \mathrm{~h}$

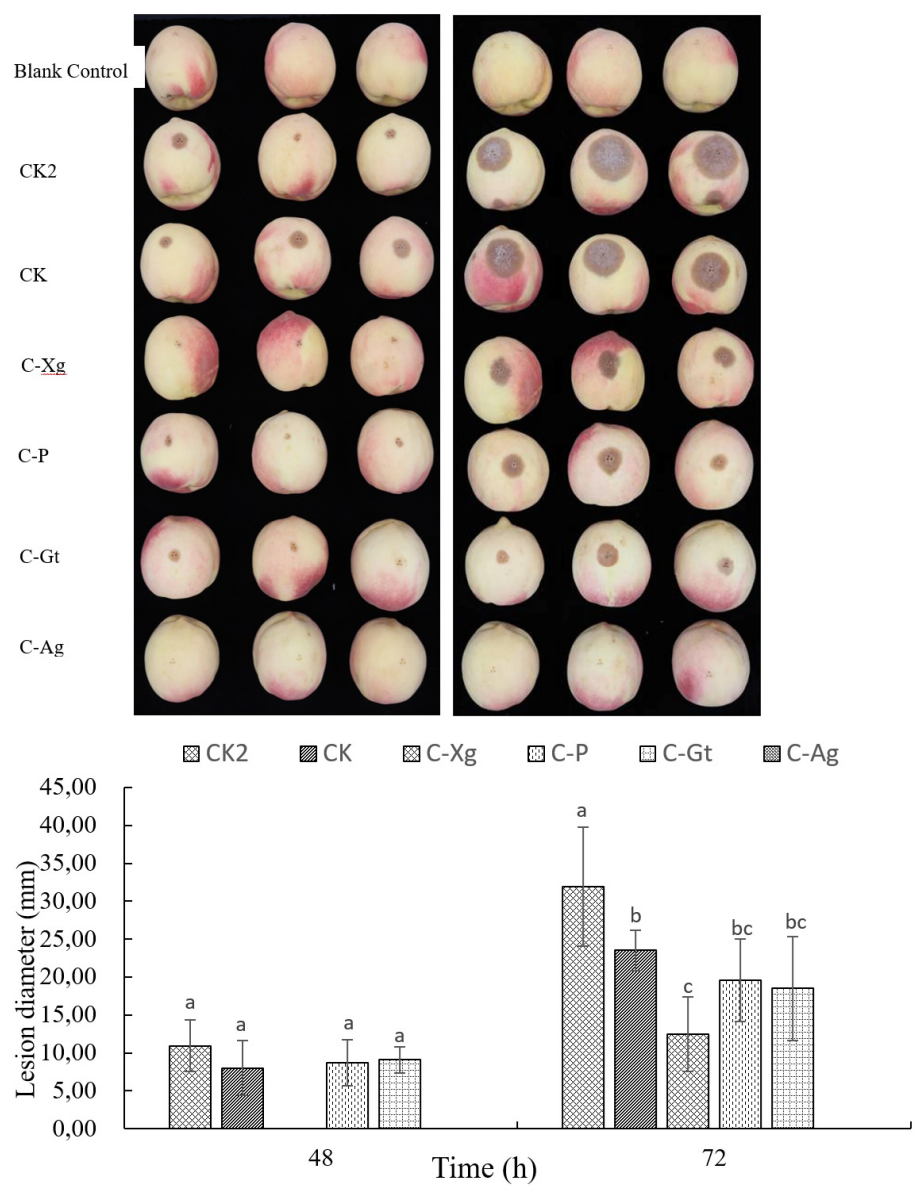

Figure 4. Effects of film solutions coating on the lesion diameter of peach fruits. 

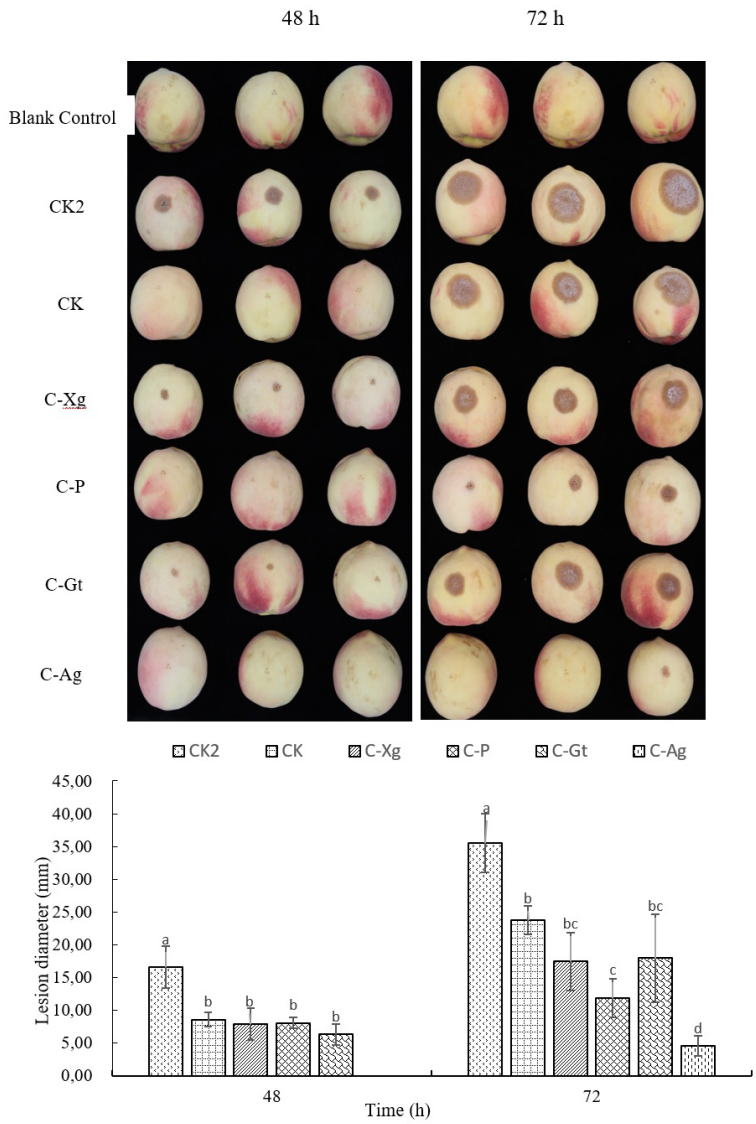

Figure 5. Effects of film fumigation on the lesion diameter of peach fruits.

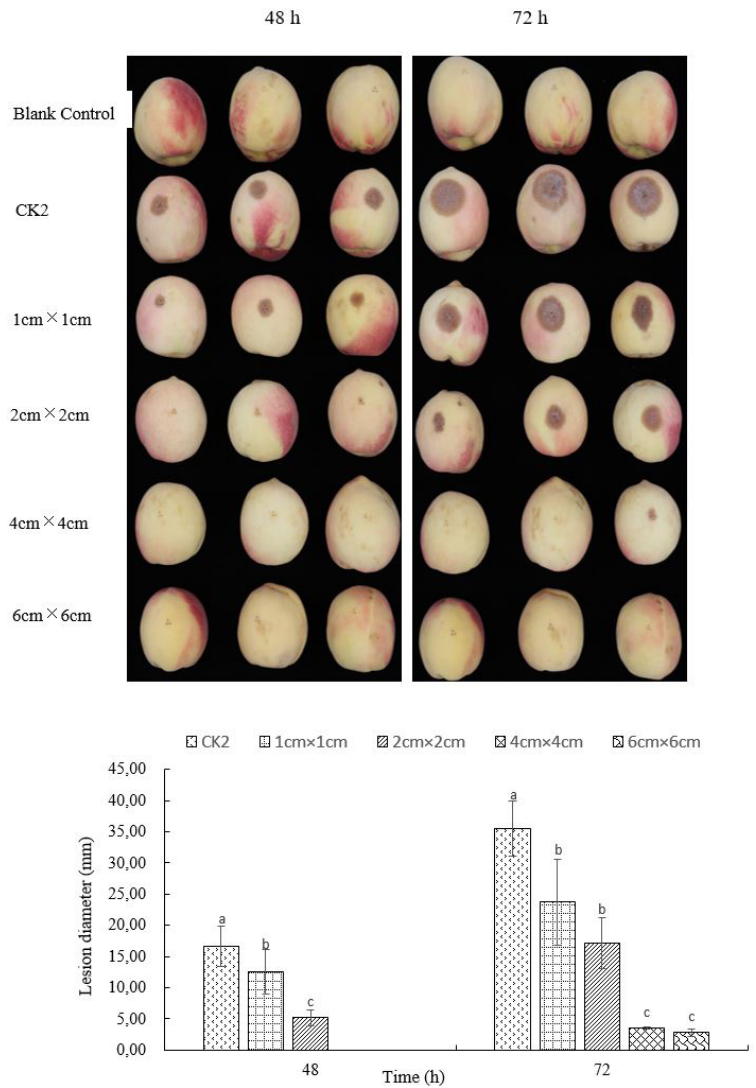

Figure 6. Effect of C-Ag film size on the lesion diameter of peach fruits. 


\section{Conclusion}

Thyme essential oil contained a large number of alkenes, phenols and alcohols compounds and possessed good inhibition effect on Monilinia fructicola of peach fruit. The addition of xanthan gum, pullulan, gum tragacanth and arabic gum into chitosan based essential oil composite film changed the physical properties and chemical structure of composite film. Particularly, arabic gum was most effective to improve the hydrogen bonding interaction among film matrix and stabilized the antifungal effect of thyme essential oil in vitro and in vivo. The electrostatic interaction between arabic gum and chitosan could be the main reason which delayed the release of thyme essential oil from composite film. The work provided a reference for the further development of controlled release and antifungal active packaging.

\section{Acknowledgements}

The work was mainly supported by Shandong "Double Tops” Program (No.SYT2017XTTD04), Incubation Program of Youth Innovatino in Shandong Province, Shandong College and Universities Plan of Youth Innovation Science and Technology Program (2020KJE007).

\section{References}

Ali, A., Yeoh, W. K., Forney, C. F., \& Siddiqui, M. W. (2018). Advances in postharvest technologies to extend the storage life of minimally processed fruits and vegetables. Critical Reviews in Food Science and Nutrition, 58(15), 2632-2649. http://dx.doi.org/10.1080/10408398. 2017.1339180. PMid:29072844.

Brahmi, F., Abdenour, A., Bruno, M., Silvia, P., Alessandra, P., Danilo, F., Drifa, Y.-G., Fahmi, E. M., Khodir, M., \& Mohamed, C. (2016). Chemical composition and in vitro antimicrobial, insecticidal and antioxidant activities of the essential oils of Mentha pulegium L. and Mentha rotundifolia (L.) Huds growing in Algeria. Industrial Crops and Products, 88, 96-105. http://dx.doi.org/10.1016/j.indcrop.2016.03.002.

De Lisi, A., Tedone, L., Montesano, V., Sarli, G., \& Negro, D. (2011). Chemical characterization of Thymus populations belonging from Southern Italy. Food Chemistry, 125(4), 1284-1286. http://dx.doi. org/10.1016/j.foodchem.2010.10.011.

Elshafie, H. S., Emilia, M., Ippolito, C., Laura, M. D., \& Vincenzo, D. F. (2015). In vivo antifungal activity of two essential oils from mediterranean plants against postharvest brown rot disease of peach fruit. Industrial Crops and Products, 66, 11-15. http://dx.doi. org/10.1016/j.indcrop.2014.12.031.

Grandetovar, C. D., Chaveslopez, C., Serio, A., Rossi, C., \& Paparella, A. (2018). Chitosan coatings enriched with essential oils: effects on fungi involved in fruit decay and mechanisms of action. Trends in Food Science \& Technology, 78, 61-71. http://dx.doi.org/10.1016/j. tifs.2018.05.019.

Hosseini, S. F., Rezaei, M., Zandi, M., \& Farahmandghavi, F. (2015). Bio-based composite edible films containing Origanum vulgare L. essential oil. Industrial Crops and Products, 67, 403-413. http:// dx.doi.org/10.1016/j.indcrop.2015.01.062.

Kaewklin, P., Siripatrawan, U., Suwanagul, A., \& Lee, Y. S. (2018). Active packaging from chitosan-titanium dioxide nanocomposite film for prolonging storage life of tomato fruit. International Journal of Biological Macromolecules, 112, 523-529. http://dx.doi.org/10.1016/j. ijbiomac.2018.01.124. PMid:29410369.
Lian, H., Peng, Y., Shi, J., \& Wang, Q. (2019). Effect of emulsifier hydrophilic-lipophilic balance (HLB) on the release of thyme essential oil from chitosan films. Food Hydrocolloids, 97, 105213. http://dx.doi.org/10.1016/j.foodhyd.2019.105213.

Lian, H., Shi, J., Zhang, X., \& Peng, Y. (2020). Effect of the added polysaccharide on the release of thyme essential oil and structure properties of chitosan based film. Food Packaging and Shelf Life, 23, 100467. http://dx.doi.org/10.1016/j.fpsl.2020.100467.

Lima, M. D., Carneiro, L. C., Bianchini, D., Dias, A. R., Zavareze, E. D., Prentice, C., \& Moreira, A. D. (2017). Structural, thermal, physical, mechanical, and barrier properties of chitosan films with the addition of xanthan gum. Journal of Food Science, 82(3), 698705. http://dx.doi.org/10.1111/1750-3841.13653. PMid:28218968.

Liu, C., Yin, X., Wang, Q., Peng, Y., Ma, Y., Liu, P., \& Shi, J. (2018). Antagonistic activities of volatiles produced by two Bacillus strains against Monilinia fructicola in peach fruit. Journal of the Science of Food and Agriculture, 98(15), 5756-5763. http://dx.doi.org/10.1002/ jsfa.9125. PMid:29756313.

Mir, A. A., Bandral, J. D., \& Sood, M. (2018). Effect of active packaging on quality and shelf life of peach fruits. The Pharma Innovation Journal, 7(4), 1076-1082.

Munhuweyi, K., Caleb, O. J., Lennox, C. L., Van Reenen, A. J., \& Opara, U. L. (2017). In vitro, and, in vivo, antifungal activity of chitosanessential oils against pomegranate fruit pathogens. Postharvest Biology and Technology, 129, 9-22. http://dx.doi.org/10.1016/j. postharvbio.2017.03.002.

Nascimento, C., Rodrigues, A., \& Silva, L. (2020). Development of a dehydrated product with edible film characteristics from mammee apple (Mammea americana L.) using Refractance Window drying. Food Science and Technology, 40(1), 245-249. http://dx.doi. org/10.1590/fst.36218.

Nikkhah, M., Hashemi, M., Habibi Najafi, M. B., \& Farhoosh, R. (2017). Synergistic effects of some essential oils against fungal spoilage on pear fruit. International Journal of Food Microbiology, 257, 285-294. http://dx.doi.org/10.1016/j.ijfoodmicro.2017.06.021. PMid:28763743.

Peng, Y., \& Li, Y. (2014). Combined effects of two kinds of essential oils on physical, mechanical and structural properties of chitosan films. Food Hydrocolloids, 36, 287-293. http://dx.doi.org/10.1016/j. foodhyd.2013.10.013.

Peng, Y., Wang, Q., Shi, J., Chen, Y., \& Zhang, X. (2020). Optimization and release evaluation for tea polyphenols and chitosan composite films with regulation of glycerol and Tween. Food Science and Technology, 40(1), 162-170. http://dx.doi.org/10.1590/fst.34718.

Perdones, A., Sanchez-Gonzalez, L., Chiralt, A., \& Vargas, M. (2012). Effect of chitosan lemon essential oil coatings on storage-keeping quality of strawberry. Postharvest Biology and Technology, 70, 32-41. http://dx.doi.org/10.1016/j.postharvbio.2012.04.002.

Priyadarshi, R., Sauraj, Kumar, B., Deeba, F., Kulshreshtha, A., \& Negi, Y. S. (2018). Chitosan films incorporated with apricot (Prunus armeniaca) kernel essential oil as an active food packaging material. Food Hydrocolloids, 85, 158-166. http://dx.doi.org/10.1016/j. foodhyd.2018.07.003.

Rahimi, R., Valizadehkaji, B., Khadivi, A., \& Shahrjerdi, I. (2019). Effect of chitosan and thymol essential oil on quality maintenance and shelf life extension of peach fruits cv. 'Zaferani'. Journal of Horticulture and Postharvest Research, 2(2), 143-156.

Santoro, K., Maghenzani, M., Chiabrando, V., Bosio, P., Gullino, M. L., Spadaro, D., \& Giacalone, G. (2018). Thyme and savory essential oil vapor treatments control brown rot and improve the storage quality of peaches and nectarines, but could favor gray mold. Foods, 7(1), 7. http://dx.doi.org/10.3390/foods7010007. PMid:29303966. 
Santoso, B., Hazirah, R., Priyanto, G., Hermanto, D., \& Sugito, D. (2019). Utilization of Uncaria gambir Roxb filtrate in the formation of bioactive edible films based on corn starch. Food Science and Technology, 39(4), 837-842. http://dx.doi.org/10.1590/fst.06318.

Shi, J., Yu, Z., Cao, J., Zhu, S., Zhang, L., \& Peng, Y. (2020). Exogenous nitric oxide enhances disease resistance by nitrosylation and inhibition of S-nitrosoglutathione reductase in peach fruit. Frontiers of Plant Science, 11, 543. http://dx.doi.org/10.3389/fpls.2020.00543. PMid:32670301.

Shih, C. M., Shieh, Y. T., \& Twu, Y. K. (2009). Preparation and characterization of cellulose/chitosan blend films. Carbohydrate Polymers, 78(1), 169-174. http://dx.doi.org/10.1016/j.carbpol.2009.04.031.

Song, X., Cheng, L., \& Tan, L. (2019). Edible iron yam and maize starch convenient food flavoring packaging films with lemon essential oil as plasticization. Food Science and Technology, 39(4), 971-979. http:// dx.doi.org/10.1590/fst.13118.

Tan, C., Xie, J., Zhang, X., Cai, J., \& Xia, S. (2016). Polysaccharidebased nanoparticles by chitosan and gum arabic polyelectrolyte complexation as carriers for curcumin. Food Hydrocolloids, 57, 236-245. http://dx.doi.org/10.1016/j.foodhyd.2016.01.021.

Tsai, R. Y., Chen, P. W., Kuo, T. Y., Lin, C. M., Wang, D. M., Hsien, T. Y., \& Hsieh, H. (2014). Chitosan/pectin/gum Arabic polyelectrolyte complex: Process-dependent appearance, microstructure analysis and its application. Carbohydrate Polymers, 101, 752-759. http:// dx.doi.org/10.1016/j.carbpol.2013.10.008. PMid:24299835.
Wang, K., Li, T., Chen, S., Li, Y., \& Rashid, A. (2020). The biochemical and molecular mechanisms of softening inhibition by chitosan coating in strawberry fruit (Fragaria $\times$ ananassa) during cold storage. Scientia Horticulturae, 271, 109483. http://dx.doi.org/10.1016/j. scienta.2020.109483.

Xu, Q., Xing, Y., Che, Z., Guan, T., Zhang, L., Bai, Y., \& Gong, L. (2013). Effect of chitosan coating and oil fumigation on the microbiological and quality safety of fresh-cut pear. Journal of Food Safety, 33(2), 179-189. http://dx.doi.org/10.1111/jfs.12038.

Xu, T., Gao, C. C., Feng, X., Wu, D., Meng, L., Cheng, W., Zhang, Y., \& Tang, X. (2020). Characterization of chitosan based polyelectrolyte films incorporated with OSA-modified gum arabic-stabilized cinnamon essential oil emulsions. International Journal of Biological Macromolecules, 150, 362-370. http://dx.doi.org/10.1016/j. ijbiomac.2020.02.108. PMid:32057867.

Xu, T., Gao, C., Yang, Y., Shen, X., Huang, M., Liu, S., \& Tang, X. (2018). Retention and release properties of cinnamon essential oil in antimicrobial films based on chitosan and gum arabic. Food Hydrocolloids, 84, 84-92. http://dx.doi.org/10.1016/j.foodhyd.2018.06.003.

Zheng, M., Shi, J., Shi, J., Wang, Q., \& Li, Y. (2013). Antimicrobial effects of volatiles produced by two antagonistic Bacillus strains on the anthracnose pathogen in postharvest mangos. Biological Control, 65(2), 200-206. http://dx.doi.org/10.1016/j. biocontrol.2013.02.004. 